\title{
Ultrasonic-assisted Dissolution of Vegetable Oils With Tetrabutylammonium Hydroxide for Multielemental Analysis by Inductively Coupled Plasma Mass Spectrometry
}

\author{
Juan Daniel Ruiz-Díaz, Marianela Savio, Mario F. Moyano, Ernesto E. Verni, Luis D. Martinez, and Raúl A. Gil* \\ Instituto de Química de San Luis (INQUISAL). Centro de Ciencia Técnica San Luis - \\ Área de Química Analítica, Facultad de Química Bioquímica y Farmacia, \\ Universidad Nacional de San Luis. San Luis, Argentina (5700)
}

\section{INTRODUCTION}

Trace metal determination has long been regarded as one of the principle tasks in areas of chemical analysis. At the early stage of instrumental development, total concentration was assessed in a variety of samples, including environmental, biological, and clinical, among others. With the power of newer analytical techniques, such as inductively coupled plasma mass spectrometry (ICP-MS), accurate quantitative results can now be obtained at ultra-trace levels not only for metals, but also for metalloids and several non-metals (1-4). However, ICP-MS has some limitations with regard to biological samples and food analysis: the high concentration of the organic matrix often results in matrix interferences and/or spectral interferences from polyatomic ions (5). These effects may be eliminated or minimized by the use of alternative isotopes and/or interference correction equations. Moreover, prior to analysis by ICP-MS, food samples must be decomposed with appropriate methods with the digests containing reduced amounts of carbon residues. However, sample digestion is a critical step in most analytical methods for routine determination of chemical elements in food samples. For instance, closedvessel acid decomposition in microwave oven systems provides fast and efficient sample digestion, and the risk of sample contamina-

\footnotetext{
*Corresponding autbor.

E-mail:ragil@unsl.edu.ar
}

\begin{abstract}
A novel, simple, and rapid method is presented for the determination of $\mathrm{B}, \mathrm{Cl}, \mathrm{Ga}, \mathrm{Ge}$, As, $\mathrm{Br}, \mathrm{Se}, \mathrm{Sn}, \mathrm{Sb}, \mathrm{I}, \mathrm{Te}, \mathrm{Pb}$, and $\mathrm{Bi}$ in vegetable oil samples by inductively coupled plasma mass spectrometry (ICP-MS) after sample solubilization with tetrabutylammonium hydroxide (TBAH) in an ultrasonic bath. Sample introduction was accomplished after dilution in water with a high-performance microconcentric nebulizer and a cooled spray chamber. The sample was mixed with TBAH, kept in an ultrasonic bath with heat for half an hour, and then diluted with nitric acid to form an aqueous solution. External calibration against aqueous standard solutions, without TBAH, was used for quantification of a number of elements. However, external calibration with TBAH allowed the determination of all analytes with good accuracy. Comparison of the obtained results with microwave-assisted digestion was performed by linear regression.
\end{abstract}

tion and loss of analytes by volatilization are practically eliminated (6-7). Another alternative to aid sample solubilization is ultrasound application with adequate reagents (8).

As an alternative approach for the sample preparation of organic materials, the use of alkaline reagents has been reported $(9,10)$. This treatment was applied with success to the multielemental analy- sis of biological and food samples by ICP-MS $(11,12)$.

A vegetable oil is a triglyceride extracted from a plant. The term 'vegetable oil' refers only to plant oils that are liquid at room temperature, or are broadly defined without regard to a substance's state of matter at a given temperature. The production process of vegetable oil involves the removal of oil from plant components, typically seeds. This can be done via mechanical extraction using an oil mill or chemical extraction using a solvent. The extracted oil can then be purified and, if required, refined or chemically altered. The presence of metals in edible oils occurs through natural contamination and during the refining process. Specific to refining is the introduction of nickel, which is used as a hardening agent (13). The presence of certain metals in the final, refined oil is undesirable because the metals can facilitate oxidative degradation of the oil and decrease shelf life (14). Several works described the analysis of vegetable oils $(10,15-18)$; however, the determination of trace elements in vegetable oils is hampered due to their low concentrations, thus requiring sensitive instrumental methods. Moreover, their high viscosity makes it difficult to introduce the sample into the instrument, and the high organic content of the oil matrix increases the possibility of interference during analysis.

To obtain an adequate test sample, the oil must first be converted into an aqueous sample capable of 
being aspirated by the nebulizer (19). Conventionally, organic samples are submitted to wet digestion in acid media with the aid of microwave heating (6). Following that scheme, robust results can be obtained, but some issues must be taken into consideration. Among them is the low acid tolerance of ICP-MS, which leads to high dilution factors and the potential risk of contamination.

In a previous work (10), we optimized a single-step procedure for trace element determination of edible oils after treatment with tetramethylammonium hydroxide (TMAH). Small amounts of TMAH were used, resulting in high sensitivity toward $\mathrm{Cu}, \mathrm{Ge}, \mathrm{Mn}, \mathrm{Mo}, \mathrm{Ni}$, $\mathrm{Sb}, \mathrm{Sr}, \mathrm{Ti}$, and $\mathrm{V}$.

The aim of the present work was to develop a new method for the determination of metalloids and non-metal elements (B, Cl, Ga, Ge, $\mathrm{As}, \mathrm{Br}, \mathrm{Se}, \mathrm{Sn}, \mathrm{Sb}, \mathrm{I}, \mathrm{Te}, \mathrm{Pb}$, and $\mathrm{Bi}$ ) in vegetable oils by ICP-MS, following sample preparation with tetrabutylammonium hydroxide (TBAH) in an ultrasonic bath. The proposed method is compared with conventional microwave acid dissolution, both using external calibration. This new method requires relatively low sample dilution, resulting in high elemental concentrations in the sample solutions, and provides a simple and safe procedure.

\section{EXPERIMENTAL}

\section{Instrumentation}

A PerkinElmer ${ }^{\circledR}$ ELAN ${ }^{\circledR}$ DRC ${ }^{\text {TM }}-\mathrm{e}$ ICP-MS (PerkinElmer, Inc., Shelton, CT, USA) was used with the instrumental operating conditions listed in Table I. The argon gas with a minimum purity of $99.996 \%$ was supplied by Air Liquide S.A. (Córdoba, Argentina). An HF-resistant and high-performance polyfluoracetate nebulizer PFA-ST (ESI, Omaha, NE, USA) was coupled to a $\mathrm{PC}^{3}$ cooled sample introduction system consisting of a baffled quartz cyclonic spray chamber. The torch injector was an O-ringfree quartz injector of $1.5 \mathrm{~mm}$ i.d.

Before changing to the PFA-ST nebulizer, a performance check for sensitivity, oxide and doubly charged ion formation was carried out using a conventional cross-flow nebulizer with a Scott-type spray chamber. For comparison purposes, the samples were also digested in a START D microwave digestion system (Milestone, Sorisole, Italy), which is hermetically sealed, has a 100-mL internal volume, polytetrafluoroethylene (PTFE) reactors with a 1-cm wall thickness, and uses a two-step program (10-minute ramp up to $200{ }^{\circ} \mathrm{C}$ and 15 -minute step at $200{ }^{\circ} \mathrm{C}$ with a maximum power of $1000 \mathrm{~W}$ ). The digested samples were analyzed by ICP-MS using the conventional cross-flow PTFE nebulizer with a Scott-type spray chamber and external calibration with an internal standard. An ultrasonic (40 kHz) water bath (from Arcano, Argentina) was used.

\section{Reagents and Standard Solutions}

Distilled, de-ionized water with a resistivity of $18.2 \mathrm{M} \Omega \mathrm{cm}$, produced by a Thermo Scientific Barnstead Easypure ${ }^{\mathrm{TM}}$ RF system (Cole-Parmer, USA), was used to make all solutions. The reagents used were concentrated nitric acid (65\%v/v) from Sigma-Aldrich (Germany), methanol from Fisher-Scientific (Lawn, NJ, USA), hydrogen peroxide $(40 \% \mathrm{v} / \mathrm{v})$ from Fluka (Germany), tetrabutylammonium hydroxide $(-40 \% \mathrm{~m} / \mathrm{v})$ from Fluka (Switzerland), dimethylformamide from Acroorganics (USA), and formic acid ( $98 \% \mathrm{v} / \mathrm{v})$ from Fisher Scientific (UK). PerkinElmer ${ }^{\circledR}$ Pure Plus Atomic Spectroscopy multielement standard solutions 1 and 2, $\mathrm{Rh} 1000 \mathrm{mg} / \mathrm{L}$ mono-elemental standard solution, and $\mathrm{Ba}$ and $\mathrm{Ce}$ (ELAN® 6100 DRC ${ }^{\text {TM }}$ Setup/Stab/ Masscal Solution) (PerkinElmer, Inc., Shelton, CT USA), were used. The analyzed samples were olive oils from Mendoza, Argentina, and Barcelona, Spain.
TABLE I

Instrumental Operating Conditions for the Analysis of Vegetable Oils by ICP-MS After Ultrasonic Solubilization With TBAH

\begin{tabular}{|c|c|}
\hline Instrumentation & PerkinElmer ELAN DRC-e ICP-MS \\
\hline Sample uptake rate & $750 \mu \mathrm{L} \mathrm{min} \operatorname{mon}^{-1}$ \\
\hline Sample introduction & $\begin{array}{l}\text { Nebulizer model PFA-ST, coupled to a quartz } \\
\text { cyclonic spray chamber with internal baffle and } \\
\text { drain line, cooled with the } \mathrm{PC}^{3} \text { system }\end{array}$ \\
\hline Radiofrequency power & $1400 \mathrm{~W}$ \\
\hline \multirow[t]{4}{*}{ Gas flow rates } & Plasma, $13.5 \mathrm{~L} \mathrm{~min}^{-1}$ \\
\hline & Auxiliary, $1.2 \mathrm{~L} \mathrm{~min}^{-1}$ \\
\hline & Nebulizer, $0.68 \mathrm{~L} \mathrm{~min}^{-1}$ \\
\hline & 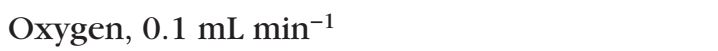 \\
\hline Sampler cone & $\mathrm{Ni}, 1.1 \mathrm{~mm}$ i.d \\
\hline Skimmer cone & $\mathrm{Ni}, 0.9 \mathrm{~mm}$ i.d. \\
\hline Scanning mode & Peak hopping \\
\hline Dwell time & $30 \mathrm{~ms}$ in standard mode \\
\hline Number of replicates & 3 \\
\hline Sample treatment & Heated ultrasonic bath $\left(90^{\circ} \mathrm{C}\right.$ and $\left.40 \mathrm{kHz}\right)$ \\
\hline
\end{tabular}




\section{Analytical Procedure}

For the optimization study, the sample solutions were prepared with $1 \%(\mathrm{v} / \mathrm{v})$ nitric acid and variable concentrations of tetrabutylammonium hydroxide (TBAH) (0.0; $1.0 ; 1.5 ; 2.5 ; 5.0$; and $20.0 \% \mathrm{v} / \mathrm{v})$, and enriched with aqueous standards to a final concentration of $100 \mu \mathrm{g} \mathrm{L}^{-1}$. Methyl alcohol was added as co-solvent $(10.0 \% \mathrm{v} / \mathrm{v})$. These solutions were used to investigate the analyte signal intensity at different TBAH concentrations, the signal intensity stability with time and optimization of the nebulizer gas, oxygen flow rate, and $\mathrm{RF}$ power. The interferences by doubly charged ions $\left(\mathrm{Ba}^{2+} / \mathrm{Ba}^{+}\right)$and oxides $\left(\mathrm{CeO}^{+} / \mathrm{Ce}^{+}\right)$were verified with solutions containing $10 \mu \mathrm{g} \mathrm{L}^{-1}$ of $\mathrm{Ba}$ and of $\mathrm{Ce}$, and increasing concentrations of TBAH (same as above). A blank solution was always measured and taken into consideration. The optimized and adopted conditions were RF power of 1200 W and nebulizer gas flow rate of $0.75 \mathrm{~L} \mathrm{~min}^{-1}$.

Using an Adventurer analytical balance (Ohaus Corporation, Parsippany, NJ, USA), approximately $0.2 \mathrm{~g}$ $(250 \mu \mathrm{L})$ of each sample was weighed into a $10-\mathrm{mL}$ polypropylene flask. TBAH $(500 \mu \mathrm{L})$ was then added and the mixture shaken vigorously in a vortex mixer. After that, the flasks were kept at $60^{\circ} \mathrm{C}$ in an ultrasonic water bath for 30 minutes. The volume was completed to $10 \mathrm{~mL}$ with $10 \%(\mathrm{v} / \mathrm{v})$ methanol. For the microwave digestion procedure, about $0.5 \mathrm{mg}$ of each sample was mixed with $7 \mathrm{~mL}$ of $\mathrm{HNO}_{3}$ and $1 \mathrm{~mL}$ of $\mathrm{H}_{2} \mathrm{O}_{2}$ in PTFE reactors that were then submitted to the temperature program. After digestion was completed, the samples were diluted to $50 \mathrm{~mL}$ with ultrapure water.

For external calibration with aqueous standards, the solutions were prepared in $1 \%(\mathrm{v} / \mathrm{v})$ nitric acid. For calibration in an organic medium, solutions of $10 \mathrm{~mL}$ were prepared in $2.5 \%(\mathrm{v} / \mathrm{v}) \mathrm{TBAH}, 10 \%$ (v/v) methyl alcohol, and 1\% (v/v) nitric acid, then made up to $10-\mathrm{mL}$ volume with ultrapure water. The analyte concentrations were 10, 20, 50, 70, and $100 \mu \mathrm{g} \mathrm{L}^{-1}$. Rhodium ( $40 \mu \mathrm{g} \mathrm{L}^{-1}$ ) was added to all solutions as the internal standard.

\section{RESULTS AND DISCUSSION}

\section{Effect of Sample Preparation}

For trace element analysis of oil samples, different preparations were tested in order to achieve an aqueous sample. In this case, the oil samples $(250 \mu \mathrm{L})$ were prepared separately with variable amounts (250, 500, 1000, 1500, and 2000 $\mu \mathrm{L}$ ) of concentrated formic acid, dimethylformamide (DMF) and (TBAH), both with and without ultrasound.

When the samples were prepared with formic acid with and without ultrasound, both solutions remained turbid, and coalescence occurred rapidly. In the case of DMF, the sample without ultrasound did not dissolve, and two phases appeared; but when ultrasound was applied, the solution remained clear for 30 minutes. As expected, addition of water accelerated the phase separation.

The oil samples were solubilized completely within one hour in a 1:1 TBAH/water solution; further addition of water was tolerated up to $10 \mathrm{~mL}$. Heating of the samples in a water bath $\left(60^{\circ} \mathrm{C}\right)$ accelerated the dissolution process. The results showed that TBAH is an efficient reagent to solubilize vegetable oils if ultrasound and moderate heat are applied. Instead of an extensive pretreatment before analysis, such as digestion with mineral acids at elevated temperatures, sample solubilization with TBAH was very simple and fast since only moderate heating and ultrasound were needed. The samples were analyzed in screw-capped tubes, thus preventing losses, and are opened only when cooled to room temperature.

In our work, the olive oil samples were weighed and mixed in a polypropylene flask, placed into a vortex mixer with a small volume of (1:1) TBAH/water, followed by 30 minutes each of ultrasound application and heating at $60^{\circ} \mathrm{C}$. Then the samples were analyzed by ICP-MS.

\section{Instrumental Optimization}

It is well known that ion formation depends largely on the ICP temperature and time of residence in the plasma. These parameters can be handled through adequate tuning of the applied radiofrequency (RF) power and the carrier gas flow rate. Thus, a study of the ICP operating conditions is mandatory before analysis by ICP-MS. In the present study, the oil samples (spiked with $40 \mu \mathrm{g} \mathrm{L}^{-1}$ of each analyte) were treated with the recommended procedure and analyzed by ICP-MS at different RF power (Figure 1) and using a different nebulizer Ar flow rate (Figure 2). Before optimization, the ICP-MS performance was adjusted and evaluated as indicated in the user's manual of the ELAN® DRC-e ICP-MS; i.e., the Setup/Masscal solution (see Reagents section) was aspirated with a conventional cross-flow nebulizer coupled to a Scott-type spray chamber. The values of the intensities toward $\mathrm{In}, \mathrm{Mg}$, and $\mathrm{U}$ were monitored (threshold values of 25000, 5000, and $20000 \mathrm{cps,}$ respectively) as well as the ratios of $\mathrm{Ba}^{2+} / \mathrm{Ba}^{+}$and $\mathrm{CeO}^{+} / \mathrm{Ce}^{+}$(lower than $3 \%)$. Then, the conventional sample introduction system was changed using the PFA micro-nebulizer and the baffled, quartz-made cyclonic spray chamber (cooled) with an auxiliary line for adding $\mathrm{O}_{2}$. With this new configuration, the vegetable oils were introduced after treatment with the recommended procedure. Figure 1(A) shows the 


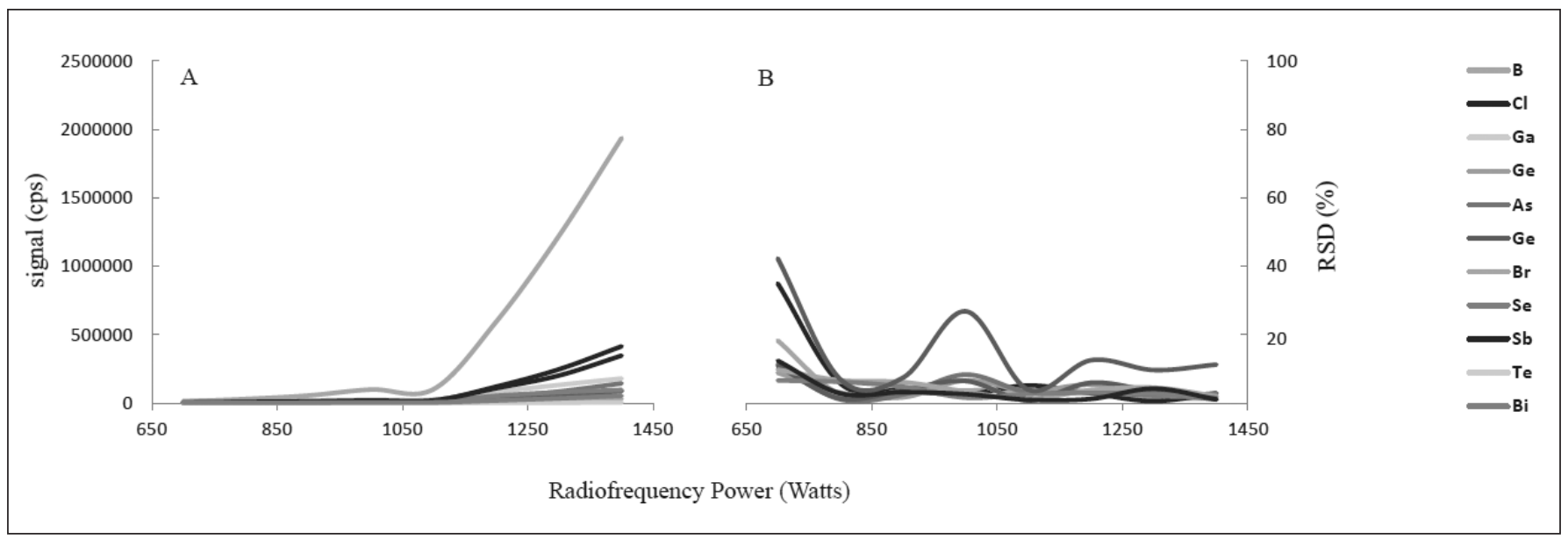

Fig. 1. (A) Effect of ICP radiofrequency power on analyte sensitivity and (B) measurement precision as \%RSD.

effect of the applied RF power on the analyte intensities. It became evident that values above $1400 \mathrm{~W}$ were needed for maximum ionization yield under the working conditions. Figure 1(B) shows that a lower relative standard deviation (RSD) can be achieved at high power. Consequently, an RF power of $1400 \mathrm{~W}$ was set for all further experiments. Although an RF power up to $1600 \mathrm{~W}$ is tolerated with the ELAN ICP-MS, we decided to work below these levels of power in order to extend the lifetime of the ICP consumables.

The second study was the optimization of the carrier flow rate (nebulizer gas), which governs the amount of sample that reaches the ICP (more energy to ionize the analytes), and also the residence time of each specie within the ICP. This compromise situation was studied (Figure 2) and an Ar flow rate of $0.68 \mathrm{~L} \mathrm{~min}^{-1}$ was used as the working condition which provided best sensitivity.

Finally, the ICP performance was evaluated in terms of the oxide ion and doubly charged ion formation rates. This study was carried out with samples prepared with increasing amounts of TBAH spiked with $1.0 \mu \mathrm{g} \mathrm{L}^{-1} \mathrm{Ba}(\mathrm{II})$ and $\mathrm{Ce}(\mathrm{III})$, and the ratios of $\mathrm{Ba}^{2+} / \mathrm{Ba}^{+}$and $\mathrm{CeO}^{+} / \mathrm{Ce}^{+}$were evaluated (Figure 3).

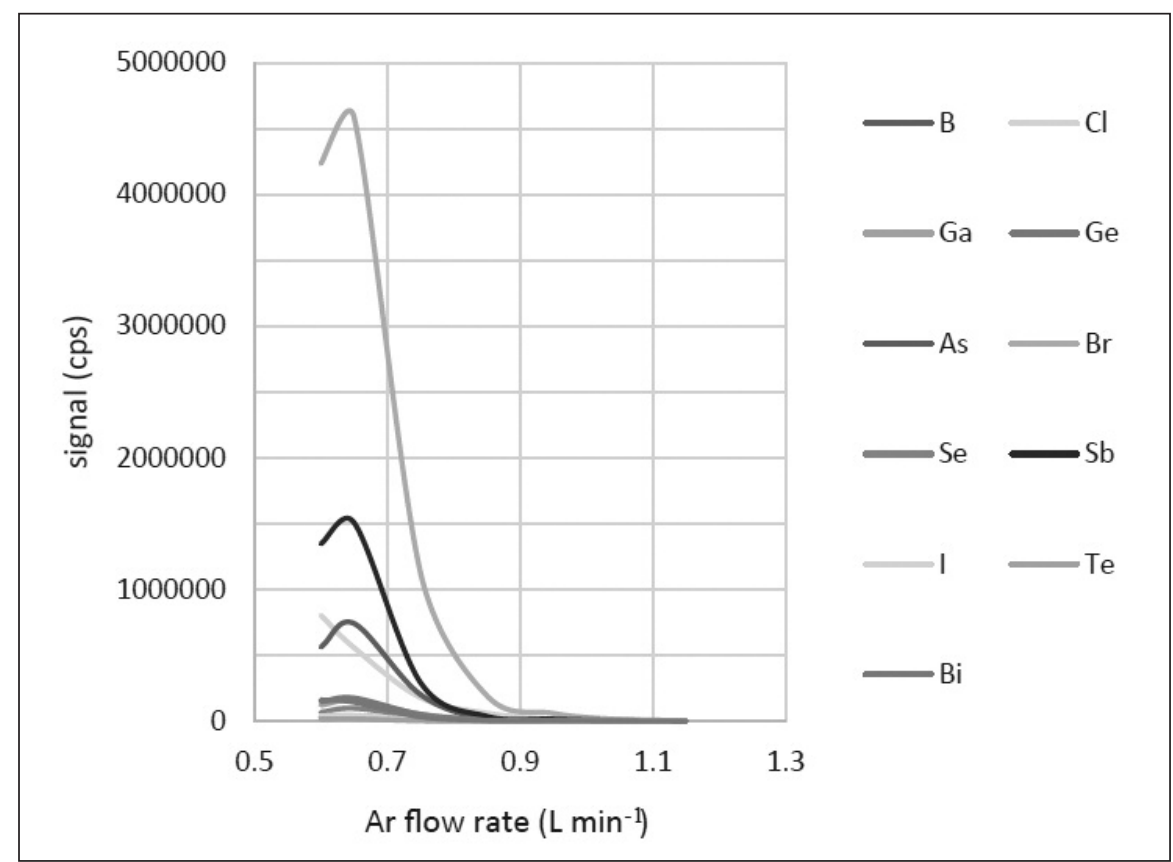

Fig. 2. Effect of Ar flow rate on analyte sensitivity, $R F$ Power $=1400$.

As can be observed, acceptable ratios (below 0.03) were obtained up to $500 \mu \mathrm{L}$ of $\mathrm{TBAH}$ in $10 \% \mathrm{vv}^{-1}$ $\mathrm{MeOH}$ mL solution.

\section{Adding $\mathrm{O}_{2}$ to Decrease the Concentration of $\mathbf{C}$}

Several authors have observed that small amounts of organic compound can raise the nebulization and transport efficiencies in comparison to aqueous solutions $(7,10$,
19-25). An additional effect is that organic solvents can increase the ionization rate of high ionization energy elements through carbon charge-transfer reactions (20). Besides, carbon derived from solvents and from the oil samples can generate instability to the ICP, but it may also condense on cones resulting in signal drift and loss of sensitivity. 


\section{Atomic Apectroscopy \\ Vol. 36(2), March/April 2015}

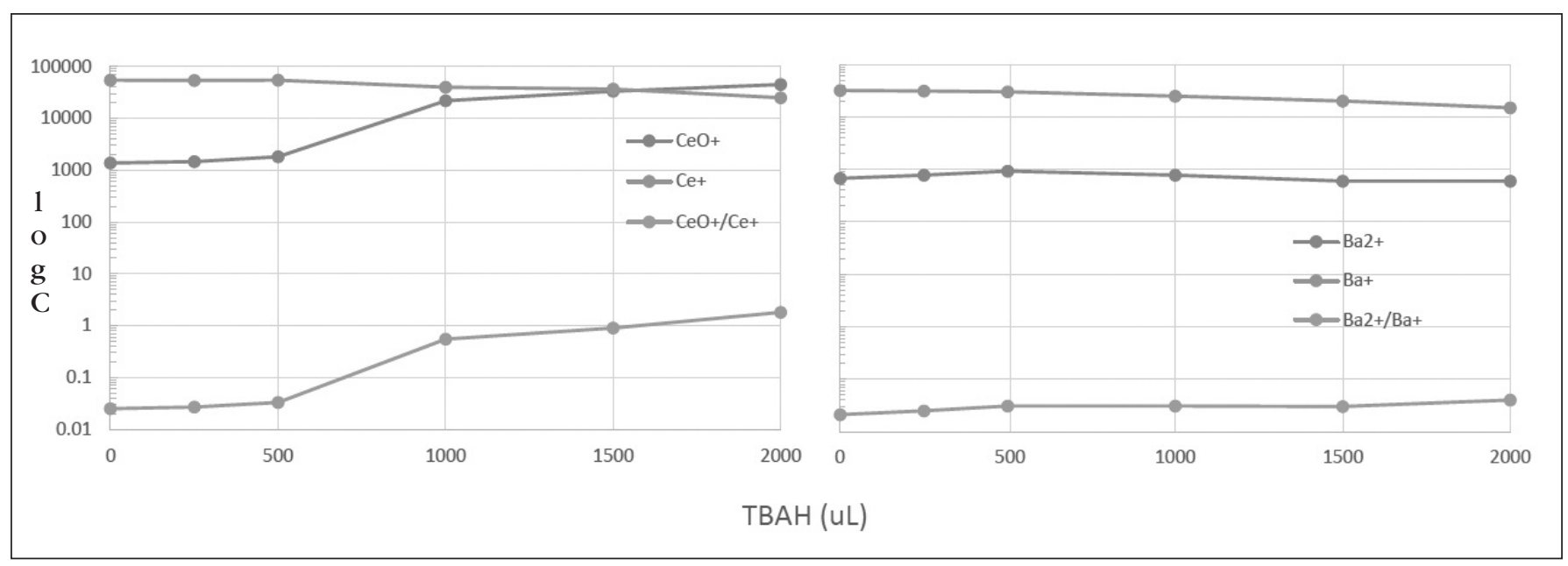

Fig. 3. Effect of added TBAH on ICP parameters of $\mathrm{CeO}^{+} / \mathrm{Ce}$ and $\mathrm{Ba}^{2+} / \mathrm{Ba}$.

Although ICP-MS operation with light solvents without the use of a cooled spray chamber is feasible, better stability is obtained if cooling is applied. Problems experienced with condensation of particulate carbon on the sampler orifice have been eliminated by the use of a low flow of oxygen into the nebulizer gas controlled by a mass flow controller (26).

This study aimed to minimize the carbon effect through the application of cooling and addition of oxygen gas after the spray chamber. The study involved monitoring the analyte signals in terms of the oxygen gas flow rate. Even though no differences were observed in the recorded signals, the observed standard deviation (\%RSD) of each measurement increased with an increase in the oxygen flow rate. Cooling the spray chamber at $+2{ }^{\circ} \mathrm{C}$ instead of at $-5^{\circ} \mathrm{C}$ is better due to the condensation of TBAH (and sample) in the drain line of the cyclonic spray chamber.

\section{Assessing Matrix Effects: Calibration Strategy}

After the optimization process, the instumental conditions (as listed in Table I) were set for all further determinations. In a first approach, the samples treated with

TABLE II

Determination of Selected Analytes in an Olive Oil Sample Through External Calibration and External Calibration With Matrix Matching

\begin{tabular}{cccc}
\hline Analyte & $\begin{array}{c}\text { Aqueous } \\
\text { Calibration }\end{array}$ & $\begin{array}{c}\text { Matrix } \\
\text { Matching }\end{array}$ & $\begin{array}{c}\text { Microwave- } \\
\text { Assisted }\end{array}$ \\
\hline $\mathrm{B}$ & $28.8 \pm 1.1$ & $2.1 \pm 1.0$ & $9.3 \pm 1.6$ \\
$\mathrm{Cl}$ & $3.9 \pm 0.1$ & $1.8 \pm 0.1$ & $1.5 \pm 0.2$ \\
$\mathrm{Ga}$ & $0.10 \pm 0.01$ & $0.020 \pm 0.01$ & $0.015 \pm 0.001$ \\
$\mathrm{Ge}$ & $<\mathrm{D} . \mathrm{L}$. & $0.02 \pm 0.01$ & $0.02 \pm 0.01$ \\
$\mathrm{As}$ & $3.50 \pm 0.10$ & $0.10 \pm 0.03$ & $0.15 \pm 0.05$ \\
$\mathrm{Br}$ & $1093 \pm 11$ & $<\mathrm{D} . \mathrm{L}$. & $<\mathrm{D} . \mathrm{L}$. \\
$\mathrm{Se}$ & $111.7 \pm 4.1$ & $3.7 \pm 0.2$ & $2.9 \pm 0.8$ \\
$\mathrm{Sn}$ & $2.0 \pm 0.1$ & $3.9 \pm 0.1$ & $4.1 \pm 1.1$ \\
$\mathrm{Sb}$ & $0.8 \pm 0.1$ & $3.9 \pm 0.6$ & $2.3 \pm 0.1$ \\
$\mathrm{I}$ & $13788 \pm 910$ & $550 \pm 21$ & $1061 \pm 25$ \\
$\mathrm{Te}$ & $20.5 \pm 1.1$ & $6.1 \pm 0.6$ & $6.1 \pm 0.9$ \\
$\mathrm{~Pb}$ & $1.20 \pm 0.10$ & $0.40 \pm 0.04$ & $1.05 \pm 0.11$ \\
$\mathrm{Bi}$ & $2.4 \pm 0.2$ & $1.4 \pm 0.5$ & $1.5 \pm 0.1$ \\
\hline
\end{tabular}

Values expressed in $\mu \mathrm{g} \mathrm{Kg}^{-1}$.

TBAH were analyzed by ICP-MS and calibrated with aqueous standards. In a second approach, calibration was performed with standards and TBAH added to equal the sample content. Finally, the samples were added with increasing amounts of multielemental standards for calibration using the standard addition method. Parallel microwaveassisted acid digestions were accomplished, and the samples were analyzed by ICP-MS with its conventional sample introduction system; i.e., cross-flow nebulizer and Scott-type spray chamber. A comparison of the obtained results for the analysis of vegetable oils using external calibration and matrix-matched external calibration is given in Table II. The results show that good agreement was found between the determination of the selected analytes in the same sample using matrix-matched standards (MM) and treatment with 
conventional acid microwave digestion and conventional introduction system.

In Figure 4, a log-log plot shows the linear regression between each approach for calibration and the results obtained after microwaveassisted acid digestion. Agreement between matrix-matched calibration (MM) and microwave acid digestion (MW) was obtained from the slope and the ordinate values (1.0111 and 0.0013 , respectively) with a regression coefficient of 0.9889 . However, a poor fit was observed for the linear regression between aqueous calibration and microwave-assisted digesiton. The outcome was that matrix-matched calibration was indispensable for preparation of the standards in the calibration process. Internal standard addition was done routinely. Simply, the results were adequate when $\mathrm{Rh}$ was added since it was corroborated experimentally in preliminary studies.

\section{Analytical Performance}

Table III shows the method of figures of merit. External matrixmatched calibrations with standard solutions and TBAH added, using ${ }^{103} \mathrm{Rh}^{+}$as the internal standard, were carried out. The detection limit (DL) was defined as 3.3 times the standard deviation of 10 measurements of the blank concentration, multiplied by the sample dilution factor. The limit of quantification defined as 3.3 times the DL can be easily obtained from the data as listed in Table III.

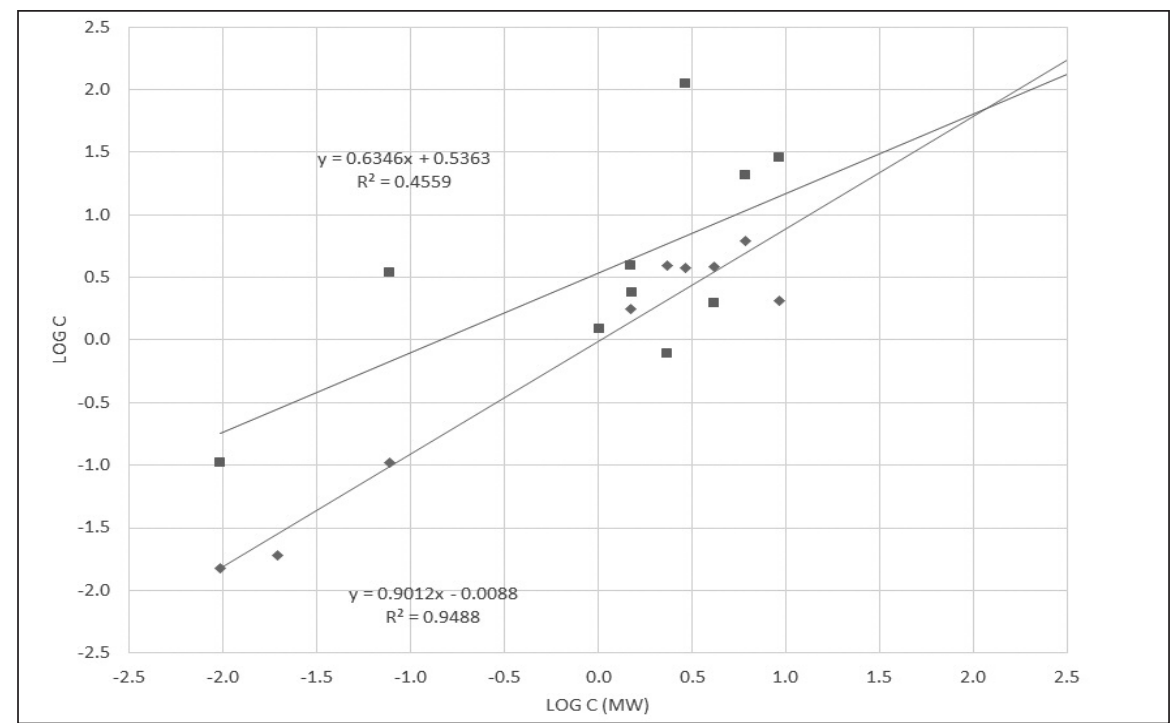

Fig. 4. Log-log plot for obtained results through the proposed method with direct aqueous calibration ( $\square$ ) and matrix matching ( $\bigcirc$ ) in comparison with microwave-assisted digestion.

\section{Analytical Application and Validation}

The proposed method was also applied to the analysis of three vegetable oils commercially available in Argentina. The selected samples were olive oils of different blends. Spiked samples were also analyzed to assess the accuracy of the method. The results (Table IV) are in agreement with the certified values of $\mathrm{Pb}, \mathrm{Sb}$, and $\mathrm{As}$ as reported by other authors $(27,28)$. However, limited information is available about non-metals and metalloids and our study is first in evaluating $\mathrm{Cl}, \mathrm{Br}, \mathrm{I}$, $\mathrm{Se}, \mathrm{Ge}, \mathrm{Ga}, \mathrm{Sn}$, and Bi concentrations in vegetable oils.

Calibration with analyte addition was carried out, and the recoveries (Table V) can be easily obtained with the matrix-matched calibration strategy.
TABLE III

Anaytical Performance of Developed Method for ICP-MS Analysis of Vegetable Oil Treated With TBAH

\begin{tabular}{lrrc}
\hline $\begin{array}{c}\text { Analyte } \\
\text { Isotope } \\
(\mathrm{m} / \mathrm{z})\end{array}$ & $\begin{array}{c}\mathrm{DL} \\
\left(\mu \mathrm{Kg}^{-1}\right)\end{array}$ & $\begin{array}{c}\% \mathrm{RSD} \\
(\mathrm{n}=3 ; \\
\left.10 \mu \mathrm{g} \mathrm{L}^{-1}\right)\end{array}$ \\
\hline $\mathrm{B}$ & 11 & 7.0 & 4.8 \\
$\mathrm{Cl}$ & 35 & 67.5 & 0.8 \\
$\mathrm{Ga}$ & 69 & 1.6 & 24 \\
$\mathrm{Ge}$ & 74 & 1.2 & 4.2 \\
$\mathrm{As}$ & 75 & 4.8 & 5.9 \\
$\mathrm{Br}$ & 79 & 104.8 & 8.1 \\
$\mathrm{Se}$ & 82 & 12.7 & 2.2 \\
$\mathrm{Sn}$ & 103 & 6.9 & 0.3 \\
$\mathrm{Sb}$ & 115 & 2.3 & 0.5 \\
$\mathrm{I}$ & 118 & 177.0 & 3.7 \\
$\mathrm{Te}$ & 121 & 39.6 & 5.9 \\
$\mathrm{~Pb}$ & 127 & 5.8 & 0.7 \\
$\mathrm{Bi}$ & 130 & 12.6 & 0.6 \\
\hline
\end{tabular}




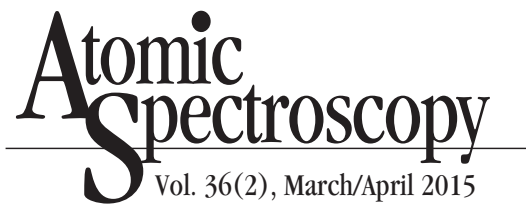

TABLE IV

Vegetable Oil Analysis by ICP-MS After Ultrasonic Solubilization in HTBA

\begin{tabular}{|c|c|c|c|}
\hline Analyte & $\begin{array}{c}\text { Olive Oil } 1 \\
\left(\mu \mathrm{g} \mathrm{Kg}^{-1}\right)\end{array}$ & $\begin{array}{c}\text { Olive Oil 2 }) \\
\left(\mu \mathrm{g} \mathrm{Kg}^{-1}\right)\end{array}$ & $\begin{array}{l}\text { Olive Oil } 3 \\
(\mu \mathrm{g} \mathrm{Kg})\end{array}$ \\
\hline B & $286.9(48.2)$ & 182.8 & 172.3 \\
\hline $\mathrm{Cl}$ & $368.0(80.6)$ & $<$ D.L. & $<$ D.L. \\
\hline $\mathrm{Ga}$ & $158.1(63.0)$ & $84.2(39.3)$ & $(0.7)$ \\
\hline Ge & $27.6 \quad(9.1)$ & $2.2 \quad(0.4)$ & $<$ D.L. \\
\hline As & $24.2 \quad(4.3)$ & $8.1 \quad(1.5)$ & $(0.5)$ \\
\hline $\mathrm{Br}$ & $<$ D.L. & 1813 (235) & $2942.1(367.9)$ \\
\hline $\mathrm{Se}$ & $29.1 \quad(9.2)$ & $41.9 \quad(8.5)$ & 42.2 \\
\hline Sn & $167.2(17.8)$ & $482.9(36.3)$ & 390.9 \\
\hline $\mathrm{Sb}$ & $263.4(40.6)$ & $393.5 \quad(2.7)$ & 386.4 \\
\hline I & <D.L. & <D.L. & $<$ D.L. \\
\hline $\mathrm{Te}$ & $3.7 \quad(1.4)$ & $4.5 \quad(1.7)$ & $(3.2)$ \\
\hline $\mathrm{Pb}$ & $1.6 \quad(0.4)$ & $22.9 \quad(8.1)$ & $<$ D.L. \\
\hline $\mathrm{Bi}$ & $1.2(0.2)$ & $<$ D.L. & $<$ D.L. \\
\hline
\end{tabular}

Values in parenthesis: standard deviation $(n=3)$.

$<$ D. L. = below detection limit.

\section{CONCLUSION}

A single-step procedure for trace element analysis of vegetable oils after ultrasonic treatment with tetrabutylammonium hydroxide (TBAH) was developed. A microconcetric pneumatic nebulizer with a cooled cyclonic spray chamber was the sample introduction system for the elemental determinations by ICP-MS with good accuracy (92$122 \%$ ) and adequate precision (RSD better than $8.1 \%)$. Small amounts of TBAH were used, resulting in high sensitivity toward $\mathrm{Pb}, \mathrm{Sb}, \mathrm{As}, \mathrm{Cl}, \mathrm{Br}$, I, Se, Ge, Ga, Sn, and Bi. The proposed method is precise, accurate, less expensive in comparison to acid digestion, and allows high sample throughput. In addition, undesirable effects of the organic load in the plasma, such as carbon deposits and plasma instability, are avoided.
TABLE V

Spike Recovery Test Using Matrix-Matched Calibration to Analyze an Olive Oil Sample

\begin{tabular}{|c|c|c|c|c|}
\hline Analyte & $\begin{array}{c}\text { Base } \\
\left(\mu \mathrm{g} \mathrm{L}^{-1}\right)\end{array}$ & $\begin{array}{l}\text { Added } \\
\left(\mu \mathrm{g} \mathrm{L}^{-1}\right)\end{array}$ & $\begin{array}{l}\text { Found } \\
\left(\mu \mathrm{g} \mathrm{L}^{-1}\right)\end{array}$ & $\begin{array}{l}\text { Recovery }^{a} \\
(\%)\end{array}$ \\
\hline \multirow[t]{3}{*}{ B } & $2.1 \pm 1.0$ & 0 & $2.1 \pm 1.0$ & - \\
\hline & $2.1 \pm 1.0$ & 5 & $7.8 \pm 1.0$ & 114 \\
\hline & $2.1 \pm 1.0$ & 50 & $52.1 \pm 3.1$ & 100 \\
\hline \multirow[t]{3}{*}{$\mathrm{Cl}$} & $1.8 \pm 0.1$ & 0 & $2.0 \pm 0.8$ & - \\
\hline & $1.8 \pm 0.1$ & 5 & $7.1 \pm 1.8$ & 106 \\
\hline & $1.8 \pm 0.1$ & 50 & $52.1 \pm 5.5$ & 101 \\
\hline \multirow[t]{3}{*}{$\mathrm{Ga}$} & $0.02 \pm 0.01$ & 0 & $0.02 \pm 0.01$ & - \\
\hline & $0.02 \pm 0.01$ & 5 & $5.00 \pm 0.21$ & 100 \\
\hline & $0.02 \pm 0.01$ & 50 & $52.10 \pm 1.01$ & 104 \\
\hline \multirow[t]{3}{*}{$\mathrm{Ge}$} & $0.02 \pm 0.01$ & 0 & $2.10 \pm 0.01$ & - \\
\hline & $0.02 \pm 0.01$ & 5 & $6.10 \pm 0.51$ & 122 \\
\hline & $0.02 \pm 0.01$ & 50 & $52.10 \pm 1.01$ & 104 \\
\hline \multirow[t]{3}{*}{ As } & $0.1 \pm 0.10$ & 0 & $2.1 \pm 0.10$ & - \\
\hline & $0.1 \pm 0.10$ & 5 & $5.8 \pm 1.01$ & 114 \\
\hline & $0.1 \pm 0.10$ & 50 & $49.1 \pm 3.01$ & 98 \\
\hline \multirow[t]{3}{*}{$\mathrm{Br}$} & < D.L. & 0 & < D.L. & - \\
\hline & < D.L. & 500 & $480 \pm 10$ & 96 \\
\hline & < D.L. & 5000 & $5020 \pm 10$ & 104 \\
\hline \multirow[t]{3}{*}{$\mathrm{Se}$} & $3.7 \pm 0.2$ & 0 & $3.7 \pm 0.2$ & - \\
\hline & $3.7 \pm 0.2$ & 5 & $8.8 \pm 0.6$ & 102 \\
\hline & $3.7 \pm 0.2$ & 50 & $52 \pm 1.1$ & 97 \\
\hline \multirow[t]{3}{*}{$\mathrm{Sn}$} & $3.9 \pm 0.1$ & 0 & $3.9 \pm 0.1$ & - \\
\hline & $3.9 \pm 0.1$ & 5 & $8.8 \pm 1.1$ & 98 \\
\hline & $3.9 \pm 0.1$ & 50 & $50.1 \pm 5.1$ & 92 \\
\hline \multirow[t]{3}{*}{$\mathrm{Sb}$} & $3.9 \pm 0.1$ & 0 & $3.9 \pm 0.1$ & - \\
\hline & $3.9 \pm 0.1$ & 5 & $8.4 \pm 0.7$ & 90 \\
\hline & $3.9 \pm 0.1$ & 50 & $54.1 \pm 2.1$ & 100 \\
\hline \multirow[t]{3}{*}{ I } & $550 \pm 21$ & 0 & $550 \pm 21$ & - \\
\hline & $550 \pm 21$ & 500 & 1550 & 100 \\
\hline & $550 \pm 21$ & 5000 & 5550 & 90 \\
\hline \multirow[t]{3}{*}{$\mathrm{Te}$} & $6.1 \pm 0.6$ & 0 & 2.1 & - \\
\hline & $6.1 \pm 0.6$ & 5 & 7.8 & 34 \\
\hline & $6.1 \pm 0.6$ & 50 & 52.1 & 92 \\
\hline \multirow[t]{3}{*}{$\mathrm{Pb}$} & $0.4 \pm 0.04$ & 0 & 2.1 & - \\
\hline & $0.4 \pm 0.04$ & 5 & 7.0 & 132 \\
\hline & $0.4 \pm 0.04$ & 50 & 52.1 & 103 \\
\hline \multirow[t]{3}{*}{$\mathrm{Bi}$} & $1.4 \pm 0.5$ & 0 & 2.1 & - \\
\hline & $1.4 \pm 0.5$ & 5 & 7.8 & 128 \\
\hline & $1.4 \pm 0.5$ & 50 & 52.1 & 101 \\
\hline
\end{tabular}

\footnotetext{
${ }^{\text {a }}$ Recovery as: [(found-base) / added] $* 100$
} 


\section{ACKNOWLEDGMENTS}

The authors would like to thank Instituto de Química de San Luis and Universidad Nacional de San Luis for financial support (PROICO UNSL-2-1512). The work was also supported by Consejo Nacional de Investigaciones Científicas y Técnicas (CONICET) through Project $\mathrm{N}^{\circ}$ PIP-112 20110100123 and Agencia Nacional de Pomoción Científica y Tecnológica (ANPCyT) through Project PICT-2010-1899.

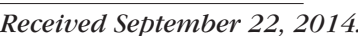

\section{REFERENCES}

1. S. Carter, A.S. Fisher, M.W. Hinds, S. Lancaster, and J. Marshall, J. Anal. At. Spectrom. 28, 1814 (2013).

2. E.H. Evans, M. Horstwood, J. Pisonero, and C.M.M. Smith, J. Anal. At. Spectrom. 28, 779 (2013).

3. O.T. Butler, W.R.L. Cairns, J.M. Cook, and C.M. Davidson, J. Anal. At. Spectrom. 29, 17 (2014).

4. E.H. Evans, J. Pisonero, C.M.M. Smith, and R.N. Taylor, J. Anal. At. Spectrom. 29, 773 (2014).

5. A. Taylor, M.P. Day, S. Hill, J. Marshall, M. Patriarca, and M. White, J. Anal. At. Spectrom. 28, 425 (2013).

6. F.G. Lepri, E.S. Chaves, M.A. Vieira, A.S. Ribeiro, A.J. Curtius, L.C.C. DeOliveira, and R.C. DeCampos, Appl. Spectrosc. Rev. 46, 175 (2011).

7. J.A. Nóbrega, M.C. Santos, R.A. de Sousa, S. Cadore, R.M. Barnes, and M. Tatro, Spectrochim. Acta Part B. 61, 465 (2006).

8. M.D. Luque de Castro, and F. PriegoCapote, Talanta. 72, 321 (2007).

9. A.A. Almeida, and J.L.F.C. Lima, J. Anal. At. Spectrom. 15, 1019 (2000).

10. M. Savio, M.S. Ortiz, C.A. Almeida, R.A. Olsina, L.D. Martinez, and R.A Gil, Food Chem. 159, 433 (2014).

11. D. Pozebon, V.L. Dressler, and A.J. Curtius, Talanta. 51, 903 (2000).

12. A.S. Ribeiro, A.L. Moretto, M.A.Z. Arruda, and S. Cadore, Mikrochim. Acta. 141, 149 (2003).

13. L.B. Allen, P.H. Siitonen, and H.C. Thompson Jr, JAOCS J Am. Oil Chem. Soc. 75, 477 (1998).

14. B. Benjellourr, T. Talou, M. Delmas, and A. Gaset, J. of American Oil Chem. Soc. 68(3), 210 (1991).

15. R. Calapaj, S. Chiricosta, G. Saija, and E. Bruno, At. Spectrosc. 9, 107 (1988).

16. D. Firestone, JAOAC Int. 77,951 (1994).

17. P.W. Hendrikse, F.J. Slikkerveer, J. Zaalberg, and A. Hautfenne, Pure Appl. Chem. 60 (1988).
18. H.J. Sun, J. American Oil Chem. Soc. (JAOCS) 66, 549 (1989).

19. J.L. Burguera, and M. Burguera, Talanta. 83, 691 (2011).

20. A.W. Boorn, R.F. Browner, Anal Chem. 54, 1402 (1982).

21. R.I. Botto, J. Anal. At. Spectrom. 8, 51 (1993).

22. I.B. Brenner, A. Zander, M. Plantz, and J. Zhu, J. Anal. At. Spectrom. 12, 273 (1997).

23. C. Duyck, N. Miekeley, C.L. Porto da Silveira, and P. Szatmari, Spectrochim. Acta Part B. 57, 1979 (2002).

24. T.D. Saint'Pierre, L. Tormen, V.L.A Frescura, and A.J. Curtius, J. Anal. At. Spectrom. 21, 1340 (2006).

25. L. Tormen, R.A. Gil, V.L.A. Frescura, L.D. Martinez, and A.J. Curtius, Spectrochim. Acta Part B. 65, 959 (2010).

26. R.C. Hutton, J. Anal. At. Spectrom. 1, 259 (1986).

27. M. Brkljaca, J. Giljanovic, and A. Prkic, Anal. Lett. 46, 2912 (2013).

28. S. Sun, B. Guo, Y. Wei, and M. Fan, Food Chem. 124, 1151 (2011). 